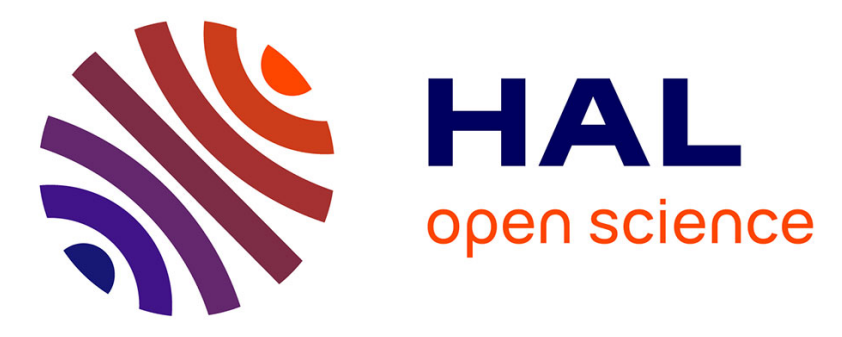

\title{
Applications of CrAlN ternary system in wood machining of Medium Density Fibreboard (MDF)
}

Yacine Benlatreche, Corinne Nouveau, Rémy Marchal, Jean-Paul Ferreira Martins, Hamid Aknouche

\section{- To cite this version:}

Yacine Benlatreche, Corinne Nouveau, Rémy Marchal, Jean-Paul Ferreira Martins, Hamid Aknouche. Applications of CrAlN ternary system in wood machining of Medium Density Fibreboard (MDF). Wear, 2009, 267 (5-8), pp.1056-1061. 10.1016/j.wear.2009.01.044 . hal-00917387

\section{HAL Id: hal-00917387 https://hal.science/hal-00917387}

Submitted on 28 Jan 2014

HAL is a multi-disciplinary open access archive for the deposit and dissemination of scientific research documents, whether they are published or not. The documents may come from teaching and research institutions in France or abroad, or from public or private research centers.
L'archive ouverte pluridisciplinaire HAL, est destinée au dépôt et à la diffusion de documents scientifiques de niveau recherche, publiés ou non, émanant des établissements d'enseignement et de recherche français ou étrangers, des laboratoires publics ou privés. 


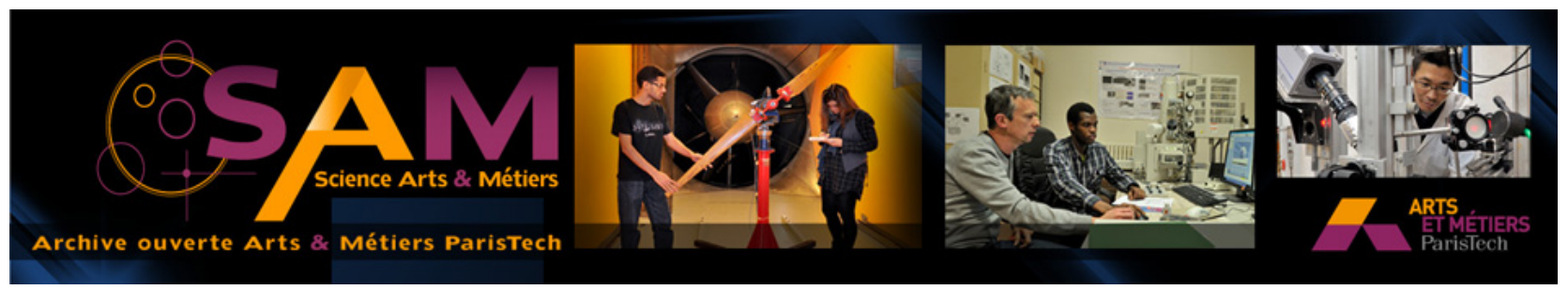

Science Arts \& Métiers (SAM)

is an open access repository that collects the work of Arts et Métiers ParisTech researchers and makes it freely available over the web where possible.

This is an author-deposited version published in: http://sam.ensam.eu

Handle ID: .http://hdl.handle.net/10985/7633

\section{To cite this version :}

Yacine BENLATRECHE, Corinne NOUVEAU, Rémy MARCHAL, Jean-Pierre FERREIRAMARTIN, Hamid AKNOUCHE - Applications of CrAIN ternary system in wood machining of Medium Density Fibreboard (MDF) - Wear - Vol. 267, n5-8, p.1056-1061 - 2009 


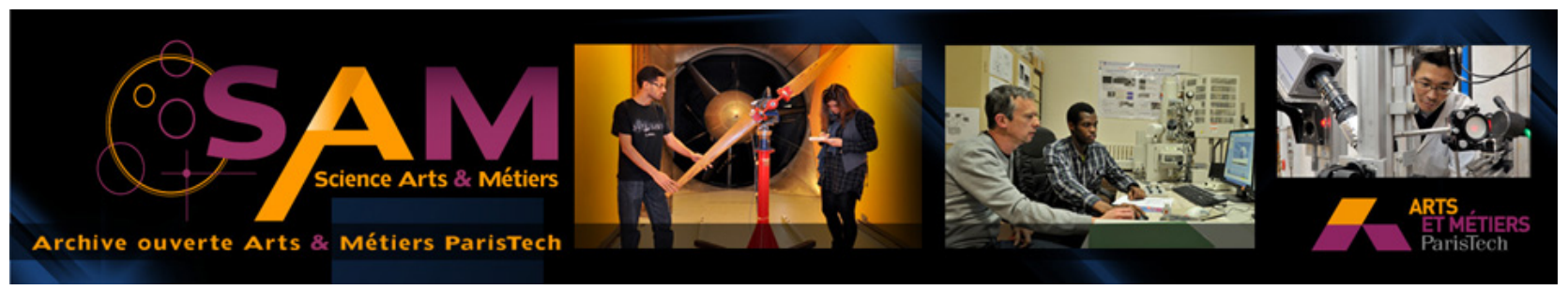

Science Arts \& Métiers (SAM)

is an open access repository that collects the work of Arts et Métiers ParisTech researchers and makes it freely available over the web where possible.

This is an author-deposited version published in: http://sam.ensam.eu Handle ID: .http://hdl.handle.net/null

\section{To cite this version :}

Yacine BENLATRECHE, Corinne NOUVEAU, Rémy MARCHAL, Jean-Pierre FERREIRAMARTIN, Hamid AKNOUCHE - Applications of CrAIN ternary system in wood machining of Medium Density Fibreboard (MDF) - Wear - Vol. 267, n5-8, p.1056-1061 - 2009 


\title{
Applications of CrAlN ternary system in wood machining of medium density fibreboard (MDF)
}

\author{
Y. Benlatreche ${ }^{\mathrm{a}}$, C. Nouveau ${ }^{\mathrm{a}, *}$, R. Marchal ${ }^{\mathrm{a}}$, J.-P. Ferreira Martins $^{\mathrm{b}}$, H. Aknouche ${ }^{\mathrm{a}}$ \\ a LaBoMaP, Arts et Métiers ParisTech, Rue Porte de Paris, F-71250, Cluny, France \\ b ISOROY, Saint-Dizier, France
}

\section{Keywords:}

CrAIN

Medium density fibreboard

Wood machining

Wear resistance

\begin{abstract}
A B S T R A C T
Nowadays, medium density fibreboard (MDF) composite wood is more and more used in the furniture industry to replace bulk wood such as oak, beech, etc. Indeed, this material presents good mechanical properties, is easy to machine, homogeneous, exists in different dimensions (thickness, etc.), is cheaper than bulk wood and finally can be covered by an adhesive decorative coat.

Nevertheless, even if this material is homogeneous, it is abrasive enough to tend to the breakdown of the conventional carbide tools employed during its routing process. That is why it is necessary to improve the wear resistance of these tools. One solution is to protect them with a hard coating.

The present study deals with the development of ternary CrAIN hard layers obtained by PVD method on carbide tools employed in second transformation of wood. CrAlN coatings have been optimized and then applied on carbide tools in routing of three types of MDF: standard, waterproof and fireproof. The aim of these wood machining tests was first to define the ability to be machined of the three kinds of MDF and second to compare the effectiveness of CrAlN coatings during the routing tests of these materials.
\end{abstract}

\section{Introduction}

The MDF is a panel of medium density fibreboard; known also as the medium, this panel is made from wood fibres and a synthetic binder. The use of MDF panels is increasing because of its good mechanical qualities, the easiness to be machined and its ability to receive numerous finishes. Moreover, the MDF is a recent industrial material which has many advantages; it is a homogeneous panel in three dimensions, aesthetic because of its fine texture, cheaper than bulk wood and it is available in various thicknesses.

The MDF panels qualities allow many and varied applications in three areas: the interior design as acoustic elements, flooring laminates, various skins, mouldings, friezes and baseboards; the furniture industry: kitchen, bathroom, libraries, cupboards and small furniture; and finally the arrangement of: offices, shops or reception areas.

However, MDF panels are abrasive, resulting in substantial tools wear of tungsten carbide. Indeed, when machining these materials, high friction forces are generated at the interface tool/MDF. As a consequence, the WC grains become detached from the edge causing the wear of the cutting tool.

\footnotetext{
* Corresponding author. Tel.: +33 3 85595335; fax: +33 385595370 .

E-mail address: nouveau@cluny.ensam.fr (C. Nouveau).
}

Several studies have been carried out in order to first understand the different mechanisms contributing to cutting edge wear of tungsten carbide tools during MDF machining [1,2], second to improve tool life using hard coatings [3,4], cryogenic treatment [5] or different kinds of tungsten carbide [6]. Nevertheless, no study has been conducted to define the machining ability of different types of MDF. Actually, according to the application, the MDF can be standard (E) (used in dry environments), waterproof $(\mathrm{H})$ (used in humid environment) or fireproof $(\mathrm{M})$ (intended for the use in dry environments subjected to regulatory fire safety).

The aim of this work was first to define the machining ability of these three types of MDF, second, hard coatings of CrAIN have been optimized by magnetron sputtering and then applied on carbide inserts employed in routing of MDF, to try to improve their service life.

\section{Experimental}

\subsection{MDF machining tests}

The experiments were performed using a three-axis industrial RECORD1 SCM S.p.A CNC router. Fig. 1 represents the tool-holder, the cutting procedure and the WC-Co tool geometry used in this work.

The MDF plates were $600 \mathrm{~mm}$ long, $200 \mathrm{~mm}$ width and $19 \mathrm{~mm}$ thick. For each machining test, the cutting conditions were $2 \mathrm{~mm}$ 


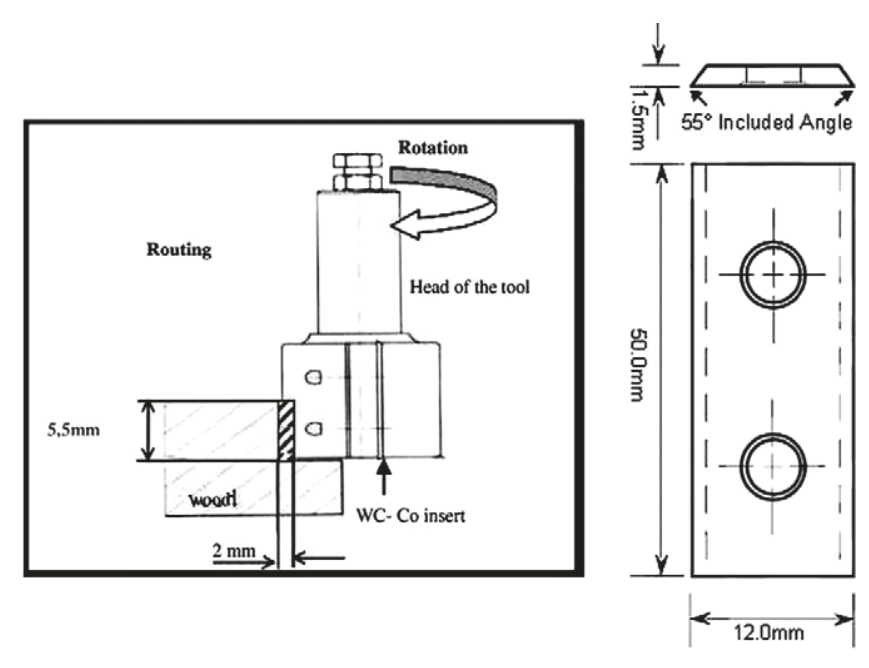

Fig. 1. (a) The tool-holder and the MDF cutting procedure and (b) the WC-Co tool geometry.

radial engagement and $5 \mathrm{~mm}$ axial engagement along the plate length. These conditions give $170 \mathrm{~m}$ of linear cutting distance. Wear measurements were made at the end of each cutting test. The final distance of MDF cutting was $1530 \mathrm{~m}$, which requires nine tests. The cutting rate was $38 \mathrm{~m} / \mathrm{s}$, the rotation rate was $18,000 \mathrm{rpm}$ and the feed rate was $15 \mathrm{~m} / \mathrm{s}$.

The cutting tools used in this study were cemented tungsten carbide inserts (WC-2\% Co) $50 \mathrm{~mm}$ long, $12 \mathrm{~mm}$ width and $1.5 \mathrm{~mm}$ thick. The cutting edge angle was $55^{\circ}$. The evaluation of wear was made by measuring the nose width (NW) using an optical microscope as shown in Fig. 2. This method has been used in different studies [7,8]. Several measurements were made along the cutting edge and an average value was calculated.

\subsection{Coatings deposition and characterizations}

The deposition of the CrAlN coatings, with different $\mathrm{Al}$ atomic percent, was carried out by a dual RF magnetron sputtering system (NORDIKO type $3500-13.56 \mathrm{MHz}$ ). A pure $\mathrm{Cr}$ and a pure $\mathrm{Al}$ target were used. To vary the Al content in the CrAlN films, we first fixed the $\mathrm{Cr}$ applied voltage at $-900 \mathrm{~V}$ and we made a variation of the $\mathrm{Al}$ one $(-300,-500,-700$ and $-900 \mathrm{~V})$, then we fixed the $\mathrm{Al}$ applied voltage at $-900 \mathrm{~V}$ and we made a variation of the $\mathrm{Cr}$ one $(-500$ and $-700 \mathrm{~V})$. The working pressure was about $4 \mu$ bar, the plasma discharge contained $80 \%$ of $\mathrm{Ar}$ and $20 \%$ of $\mathrm{N}_{2}$ and the deposition time was $90 \mathrm{~min}$. In addition to carbide inserts, different kinds of substrates were employed: silicon $10 \mathrm{~mm} \times 10 \mathrm{~mm}$ (for internal stress and thickness measurements), $\mathrm{SiO}_{2} 10 \mathrm{~mm} \times 10 \mathrm{~mm}$ (for nanoindentation: NHT from CSM Instruments with a Berkovitch indenter, sinusoidal mode employed $(1 \mathrm{~Hz}$ of frequency and $1 \mathrm{mN}$ of amplitude), max load $10 \mathrm{mN}$, load and

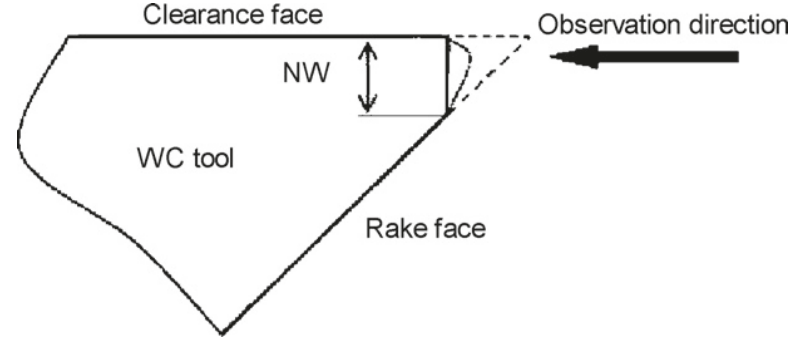

Fig. 2. Evaluation of the wear of the tool's edge by measuring the nose width (NW).

unload rate $5 \mathrm{mN} / \mathrm{min}$ )) and 90CrMoV8 steel (La Forézienne-MFLS, France $^{\mathrm{TM}}$ ) samples frequently used for tools in wood machining $20 \mathrm{~mm} \times 20 \mathrm{~mm}$ to conduct pin-on-disk tests with an applied load of $5 \mathrm{~N}$, a $100 \mathrm{Cr} 6$ ball of $5 \mathrm{~mm}$ diameter with an alternative friction each $8 \mathrm{~s}$ and a tests duration of $10 \mathrm{~min}$ to determine and compare the friction coefficient of the layers. Before deposition all the substrates were ultrasonically cleaned in ethanol. The $\mathrm{Cr}$ and $\mathrm{Al}$ targets and the samples were then etched 5 min in Ar plasma by RF and DC $(-1000 \mathrm{~V})$ discharges, respectively. The carbide tools were CrAlNcoated on both sides. The morphology and the composition of MDF samples and CrAlN coatings were determined by scanning electron microscopic (SEM) observations and EDS microanalyses (Jeol JSM-5900 LV).

\section{Results and discussion}

\subsection{CrAlN deposition and characterization}

Table 1 gives the different properties of the synthesized CrAlN coatings. The Al content contained in CrAlN films varies between 5 and 51 at.\%. We can note that in the CrAlN deposited films, the hardness varies between 15 and $36 \mathrm{GPa}$ which is more than the conventional $\mathrm{Cr}-\mathrm{N}$ system [9] or the WC-Co substrate (16 GPa) [10]. Besides, a high Young modulus (which varies between 331 and $520 \mathrm{GPa}$ ) has been calculated (same results were obtained by Kim and Lee [11]), which is good for an application of these layers on WC-Co substrates which have a Young modulus of 640 GPa [12]. Furthermore, the CrAlN layers present a high coefficient of friction (0.6-0.75) as observed in a previous study [13]. Brizuela et al. [14] showed that the friction coefficient of CrAlN coatings varied between 0.42 and 0.55 during pin-on-disc tests applying a load of $0.98 \mathrm{~N}$ to an AISI 52100 steel ball of $10 \mathrm{~mm}$ diameter, at a constant sliding speed of $0.1 \mathrm{~m} / \mathrm{s}$ under controlled humidity of $50 \%$. However the coefficient of friction stays below the substrate one of 1.0 which was determined with pin-on-disk on a sample with a high roughness (Rt close to $1 \mu \mathrm{m}$ ). As a consequence, the cutting forces during the routing process with coated tools will be lower than the ones with an unmodified tool. Low residual stresses (between -1.1 and $-3.58 \mathrm{GPa}$ ) as obtained by Reiter et al. [15] were determined, which promotes good adhesion of the CrAlN layers. In addition, these low

Table 1

Properties of CrAlN deposited films.

\begin{tabular}{|c|c|c|c|c|c|c|c|}
\hline $\begin{array}{l}\text { Al applied } \\
\text { voltage }(-V)\end{array}$ & $\mathrm{Cr}$ applied voltage $(-\mathrm{V})$ & Al content (at.\%) & Thickness ( $\mu \mathrm{m})$ & Hardness (GPa) & Young's modulus (GPa) & Friction coefficient & Residual stress (GPa) \\
\hline \multicolumn{8}{|l|}{ CrAIN } \\
\hline 300 & \multirow{4}{*}{900} & 5 & 2.1 & 26 & 410 & 0.6 & 1.1 \\
\hline 500 & & 13 & 2.5 & 26 & 410 & 0.65 & 1.52 \\
\hline 700 & & 28 & 2.7 & 23 & 380 & 0.7 & 1.43 \\
\hline & & 30 & 3 & 35 & 460 & 0.65 & 3.58 \\
\hline \multirow{2}{*}{900} & 700 & 44 & 2 & 15 & 331 & - & 1.13 \\
\hline & 500 & 51 & 2.14 & 36 & 520 & - & 1.62 \\
\hline
\end{tabular}




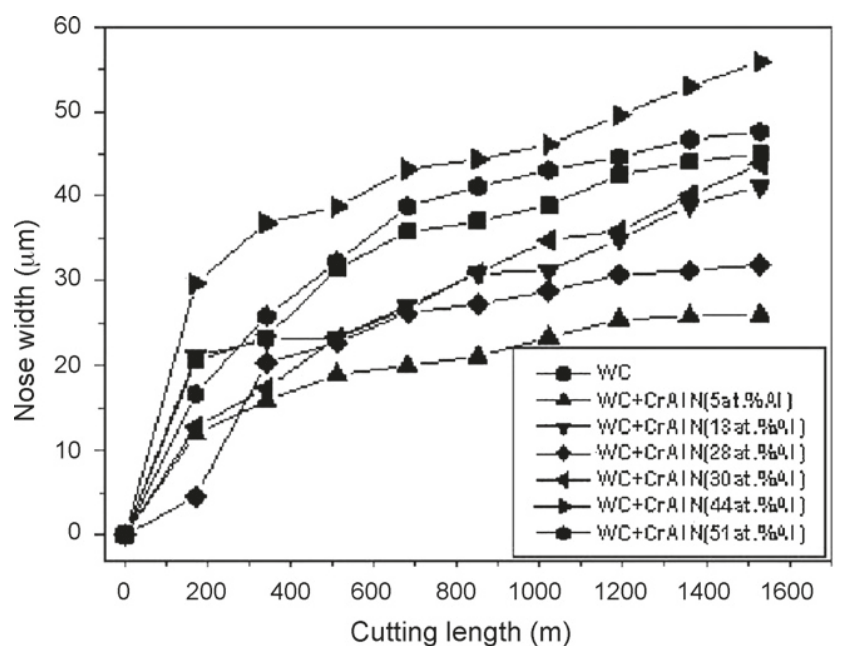

Fig. 3. Variation of the nose width as a function of the cutting length of standard MDF for tungsten carbide inserts coated with different CrAlN films.

values of residual stresses will enable us to deposit thick films. Finally, the CrAlN films thickness varied between 2 and $3.6 \mu \mathrm{m}$ which avoids rounding the cutting edge and leads to good mechanical and tribological properties.

\subsection{Machining of $M D F$}

CrAlN-coated carbide tools with different Al content were tested in standard MDF routing (Fig. 3). We can observe that the CrAlN-

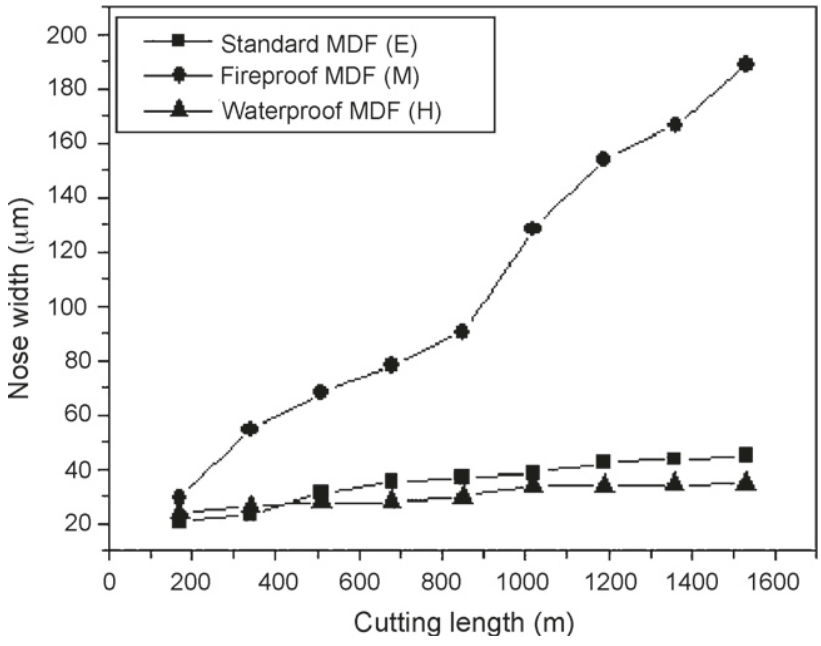

Fig. 4. The nose width vs the cutting length after the routing of the three types of MDF with conventional tools.

coated carbide insert with 5 at.\% of Al performed the best which means that this layer protects the tool more than the others. In fact with increasing of $\mathrm{Al}$, the nose width value increases. According to Bobzin et al. [16] this can be explained because the aluminium nitride films have a higher friction coefficient than the chromium nitride ones. So, it seems that the aluminium nitride content in CrAlN films increases with the Al content. Consequently, the cutting forces increase which explains the variation of the nose width of the carbide coated inserts. After these tests, we chose CrAlN films with 5 at.\% of $\mathrm{Al}$ content to be applied on carbide
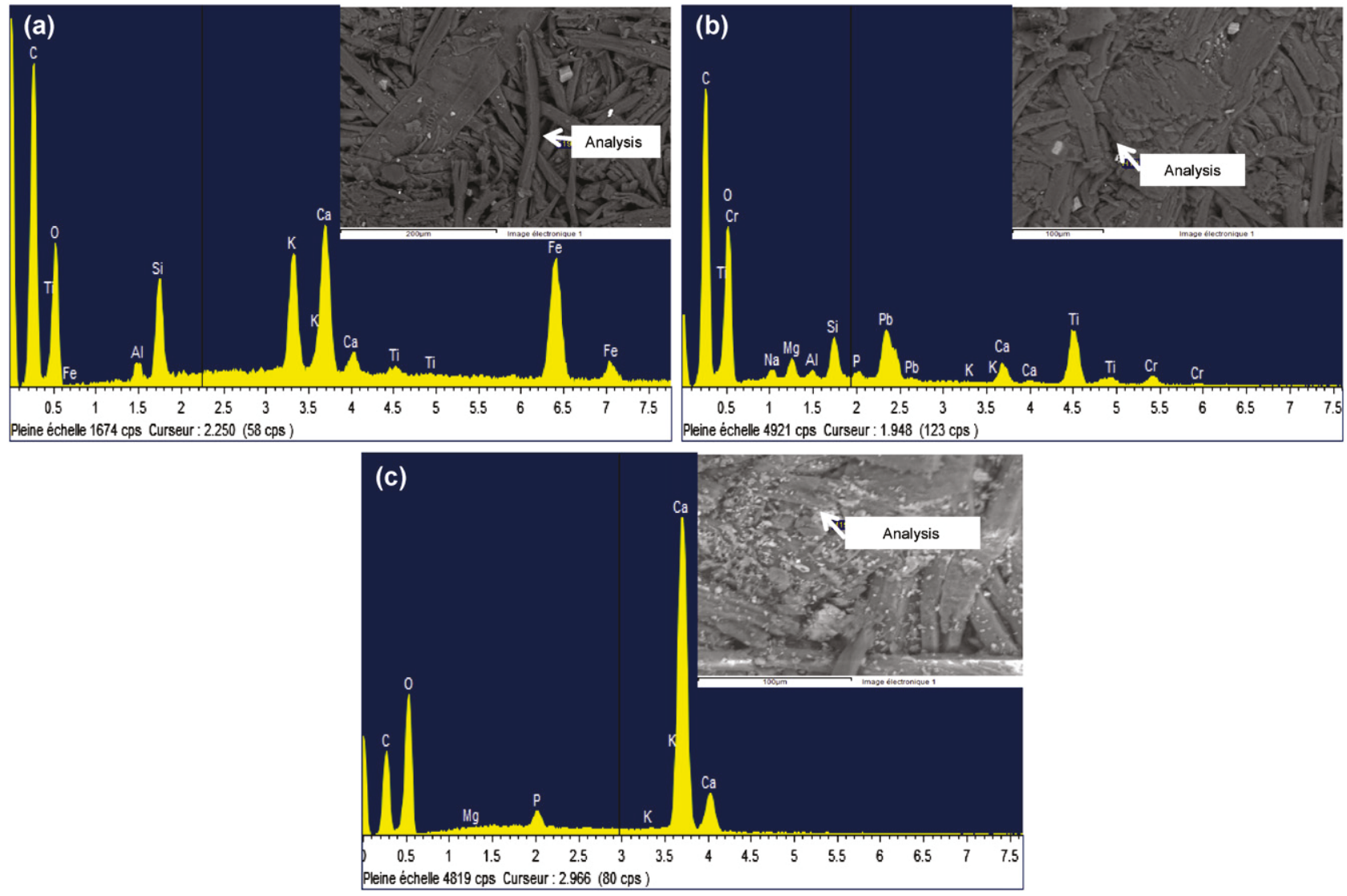

Fig. 5. EDS analysis of: (a) standard, (b) waterproof and (c) fireproof MDF. 

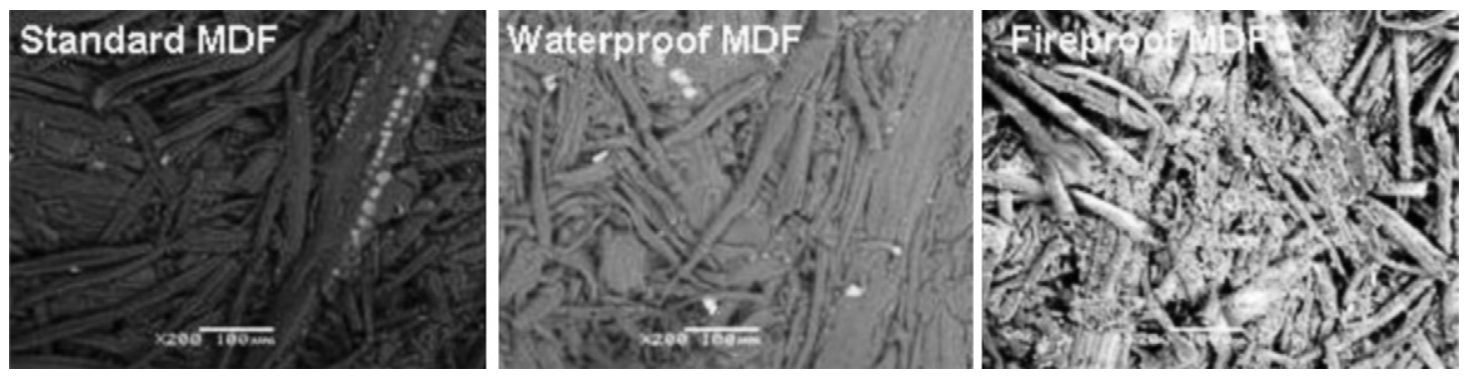

Fig. 6. SEM morphological images of the three types of MDF.

inserts dedicated to the machining of waterproof and fireproof MDF.

Fig. 4 shows the tool nose width as a function of the cutting length during the routing of the three types of MDF. We clearly see that the fireproof $\mathrm{MDF}(\mathrm{M})$ is much more abrasive than the others, the standard (E) and waterproof $(\mathrm{H})$ ones. Indeed, after $1530 \mathrm{~m}$ of cutting, the nose width is about $188 \mu \mathrm{m}$ for the fireproof MDF (M) while it is around 45 and $30 \mu \mathrm{m}$ for the standard (E) and waterproof $(\mathrm{H})$ ones respectively. In the milling of MDF, Sheikh-Ahmad et al. [7] obtained $170 \mu \mathrm{m}$ of nose width after $1525 \mathrm{~m}$ of cutting while Bai et al. [17] obtained a value of $70 \mu \mathrm{m}$ after $1500 \mathrm{~m}$ of cutting. However, we do not know which type of MDF was used in their studies. It is worthy of note that after $1530 \mathrm{~m}$ of cutting, we are always in the steady wear phase for both standard and waterproof MDF, in the contrary, we move on to the severe wear phase only after $850 \mathrm{~m}$ of cutting of fireproof MDF, which shows that this material is very abrasive.

Fig. 5 represents the EDS composition microanalysis of different MDF studied. The overall analysis gives the same composition for the three types of MDF. Unlike, the local analysis shows the presence in addition to fibreboards, of foreign elements such as calcium, metals, silicon and phosphorus, which explains the abrasive behaviour of MDF panels.

In addition to the composition analysis, a comparison between the SEM morphological images from the different types of MDF were obtained (Fig. 6). We observed that the standard and waterproof MDF have the same morphology, while the fireproof one shows a higher degree of impurities. One can suppose that this difference in the degree of impurities is the reason for the high value of the nose width obtained when machining this wood composite material.

To improve the wear resistance of tungsten carbide tools during the routing of MDF, the above mentioned CrAlN coatings ( 5 at.\% of $\mathrm{Al}$ ) have been applied on them. Fig. 7 shows the results obtained during routing of the three types of MDF using unmodified and modified carbide tools. We can observe that the CrAlN films reduced the nose width during the fireproof and standard MDF machining.

Indeed, after $1530 \mathrm{~m}$ of cutting, the value of the nose width decreases from 45 to $26 \mu \mathrm{m}$ for the standard MDF and from 188 to $148 \mu \mathrm{m}$ for fireproof MDF. We can conclude that for the routing of the fireproof MDF, the tool was well protected by the CrAIN layer and more wear resistant. As a matter of fact, we can see that we machine around 1.5 times more than with a conventional tool in this case. Even if the effectiveness of the CrAlN layer was obvious as in the case of the standard MDF, we cannot conclude on its protection against wear because as this material is not abrasive enough, we should cut enough meters to be after the steady wear phase of the tool, such experiments are in progress today. Indeed, as the CrAlN-coated tool is more wear resistant than the unmodified one during its lapping we can expect that it would be also the case after 5000 or $10,000 \mathrm{~m}$ of cutting. It is worthy of note that we are always in the steady wear phase for the standard and waterproof MDF as opposed to the fireproof MDF where we passed the severe wear phase in both cases, with or without CrAlN film. As far as the waterproof MDF is concerned, no improvement of the wear resistance was observed: the nose width was in the order of $35 \mu \mathrm{m}$ in both cases. We can suppose that as this material is not very abrasive, like the standard one, the difference in behaviour comes from the difference of composition of these two MDF. EDS microanalyses revealed that the waterproof MDF presents $\mathrm{Ti}$ or $\mathrm{Pb}$ elements while the standard one presents in some places Si element. This difference of composition could be the reason why the CrAlN coating was effective in the case of the routing of the standard MDF but not in the case of the waterproof one.

Fig. 8 shows SEM micrographs and EDS analysis of CrAIN WC-Co coated tool tested during routing of waterproof MDF. The EDS analysis confirms the presence of $\mathrm{W}$ and Co on the tool edge (Fig. 8a), of $\mathrm{Cr}$ and $\mathrm{Al}$ in the coating and of all of these elements in addition to $\mathrm{C}$ and $\mathrm{O}$ in a zone between WC-Co and CrAlN coating. However, it is not possible to know whether there was formation of new materials (oxides or carbides, etc.) during routing of MDF.

Based on the SEM images we suppose that during cutting process, the first contact occurs between the coating, which protects well the cutting edge, and the MDF plate. The good adhesion of the layer on the carbide inserts permits to decrease the detachment of WC grains from the tool edge and as a consequence the wear resistance increased.

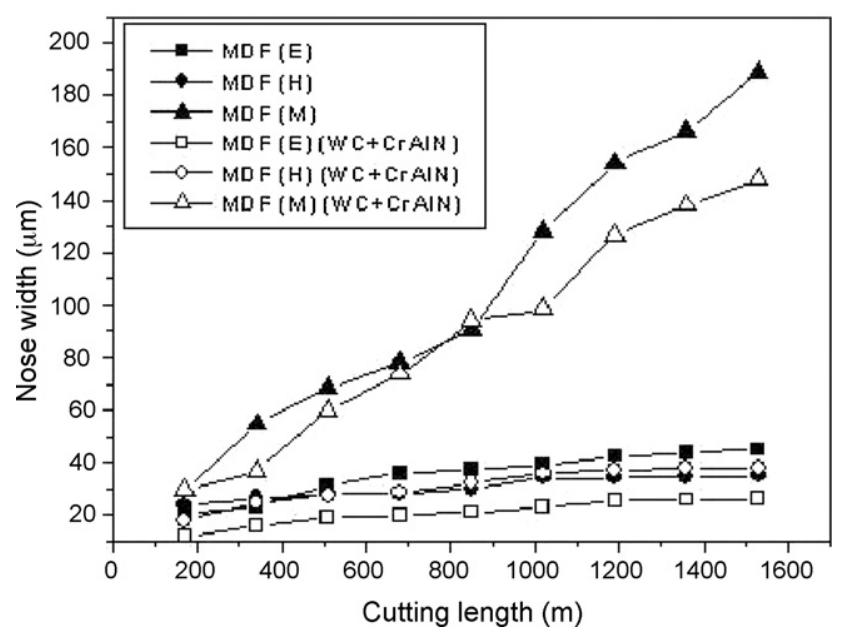

Fig. 7. Comparison of the obtained results during routing of the three types of MDF with unmodified and modified carbide tools. 

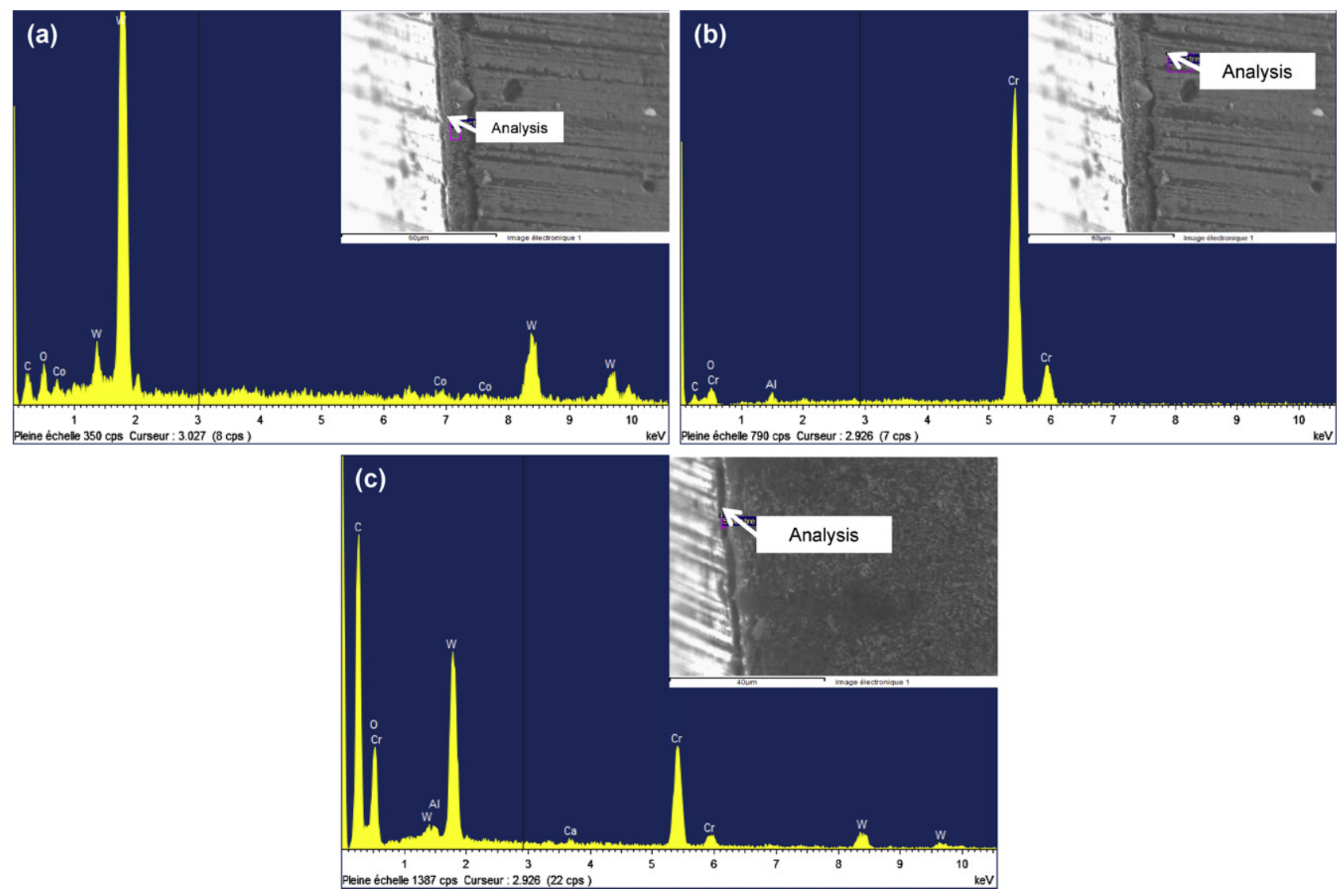

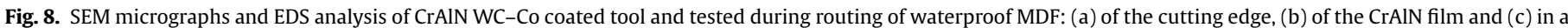
zone between WC-Co and CrAlN coating.

\section{Conclusion}

In this study three kinds of MDF were studied in order to define the machining ability of each one. In addition, CrAlN films with different $\mathrm{Al}$ content have been applied to try to improve the wear resistance of the tungsten carbide used in the routing of MDF. Based on the results presented above, the following conclusions were reached:

1. The increase of Al content in CrAlN films decreases the wear resistance of the coated-carbide inserts. Indeed, the carbide insert $\mathrm{CrAlN}$-coated with 5 at.\% of $\mathrm{Al}$ gives the smallest value of nose width.

2. The fireproof MDF is more abrasive than the standard and the waterproof ones. Actually, after $1530 \mathrm{~m}$ of cutting, the nose width is about $188 \mu \mathrm{m}$ for the fireproof MDF while it is approximately 45 and $30 \mu \mathrm{m}$ for the standard and waterproof ones respectively.

3. When compare the standard, the waterproof and the fireproof MDF, this last one has the highest degree of impurities and we suppose that it can be the reason of the abrasive behaviour of this material.

4. The use of CrAlN film with 5 at.\% of $\mathrm{Al}$ improves the wear resistance of carbide inserts during the routing of standard and fireproof MDF but not in the case of the waterproof one.

\section{Acknowledgements}

The authors want to thank especially Mr. Ferreira Martins from ISOROY of St-Dizier (France) for his advice and collaboration during this work. We also appreciated the contribution of Mr. Hamid Aknouche, PhD student in our laboratory.

\section{References}

[1] W. Darmawan, C. Tanaka, H. Usuki, T. Ohtani, Performance of coated carbide tools in turning wood-based materials: effect of cutting speeds and coating materials on the wear characteristics of coated carbide tools in turning woodchip cement board, J. Wood Sci. 47 (2001) 342-349.

[2] W. Darmawan, C. Tanaka, H. Usuki, T. Ohtani, Performance of coated carbide tools when grooving wood-based materials: effect of work materials and coating materials on the wear resistance of coated carbide tools, J. Wood Sci. 47 (2001) 94-101.

[3] T. Morita, J.Y. Sheikh-Ahmad, K. Banshoya, T. Tsutsumoto, Y. Murase, On the cutting performance of diamond-coated cemented carbide tools pretreated with Murakami $/ \mathrm{H}_{2} \mathrm{O}_{2}-\mathrm{H}_{2} \mathrm{SO}_{4}$ solution, Forest Products J. 50 (2000) 67-73.

[4] J.Y. Sheikh-Ahmad, T. Morita, Tool coatings for wood machining: problems and prospects, Forest Products J. 52 (2002) 43-51.

[5] H.A. Stewart, Cryogenic treatment of tungsten carbide reduces tool wear when machining medium density fibreboard, Forest Products J. 54 (2004) 53-56.

[6] J.Y. Sheikh-Ahmad, J.A. Bailey, The wear characteristics of some cemented tung sten carbides in machining particleboard, Wear 225-229 (1999) 256-266.

[7] J.Y. Sheikh-Ahmad, J.S. Stewart, H. Feld, Failure characteristics of diamondcoated carbides in machining wood-based composites, Wear 255 (2003) 1433-1437.

[8] C. Gottloeber, R-J. Fischer, R. Fischer, Determination of wear on cutting edges, in: Proceeding of the 15th International Wood Machining Seminar IWMS, Los Angeles, 2001, pp. 121-129.

[9] C.H. Barshilia, N. Selvakumar, B. Deepthi, K.S. Rajam, A comparative study of reactive direct current magnetron sputtered $\mathrm{CrAlN}$ and $\mathrm{CrN}$ coatings, Surf. Coat. Technol. 201 (2006) 2193-2201.

[10] J. Pirso, S. Letunovitš, M. Viljus, Friction and wear behaviour of cemented carbides, Wear 257 (2004) 257-265.

[11] G.S. Kim, S.Y. Lee, Microstructure and mechanical properties of AlCrN films deposited by CFUBMS, Surf. Coat. Technol. 201 (2006) 4361-4366.

[12] L. Pawlowski, Dépôts Physiques, Techniques Microstructures et Propriétés, Polytechniques et Universitaires Romandes Press, 2003, p. 101, ISBN 2-88074$529-2$.

[13] X.-Z. Ding, X.T. Zeng, Structural, mechanical and tribological properties of CrAlN coatings deposited by reactive unbalanced magnetron sputtering, Surf. Coat. Technol. 200 (2005) 1372-1376.

[14] M. Brizuela, A. Garcia-Luis, I. Braceras, J.I. Oñate, J.C. Sanchez-Lòpez, D. MartinezMartinez, C. Lòpez-Cartes, A. Fernandez, Magnetron sputtering of $\mathrm{Cr}(\mathrm{Al}) \mathrm{N}$ 
coatings: mechanical and tribological study, Surf. Coat. Technol. 200 (2005) 192-197.

[15] A.E. Reiter, V.H. Derflinger, B. Hanselmann, T. Bachmann, B. Sartory, Investigation of the properties of $\mathrm{Al}_{1-x} \mathrm{Cr}_{x} \mathrm{~N}$ coatings prepared by cathodic arc evaporation, Surf. Coat. Technol. 200 (2005) 2114-2122.
[16] K. Bobzin, E. Lugscheider, R. Nickel, N. Bagcivan, A. Krämer, Wear behaviour of $\mathrm{Cr}_{1-x} \mathrm{Al}_{x} \mathrm{~N}$ PVD-coatings in dry running conditions, Wear 263 (2007) 12741280.

[17] Q. Bai, Y. Yao, S. Chen, Research and development of polycrystalline diamond woodworking tools, Int. J. Refractory Met. Hard Mater. 20 (2002) 395-400. 